\title{
13
}

\section{Conclusions: Enhancing the Resilience and Sustainability of the Agriculture Sector in sub-Saharan Africa}

\section{Abebe Shimeles, Audrey Verdier-Chouchane and Amadou Boly}

\subsection{Introduction}

The decline in oil and metal commodity prices which started mid-2014 has served as an incentive for African countries to focus on agricultural issues and to make strategic choices for transforming the agriculture sector and reducing dependency on food imports (AfDB et al. 2017). In this volume on Building a Resilient and Sustainable Agriculture in subSaharan Africa, authors have reaffirmed the importance of increasing agricultural productivity, addressing the climate change challenges and promoting agro-industrialization to achieve the objectives of tackling food insecurity and industrializing Africa. In turn, this will create jobs, economic development and allow the improvement of the quality of life. Increasing agricultural productivity could be achieved through many ways, including implementation of modern technologies, appropriate land tenure and better access to land, improved agricultural mechanization and use of irrigation as well as the adoption of high-yielding crop

A. Shimeles $\bullet$ A. Verdier-Chouchane $(\bowtie) \bullet$ A. Boly African Development Bank, Abidjan, Côte d'Ivoire 
varieties. To further propel agricultural transformation in sub-Saharan Africa and face the climate change challenges, agriculture insurance, sustainable resource management plans and integrated rural development strategies could be used as efficient measures (AfDB et al. 2017). For agro-industrialization, emphasis should be given on increasing competitiveness through closing the infrastructure gap, skills gap, reforming regulations and institutions, deepening value chains, attracting foreign direct investment through preferential taxes and creation of industrial clusters and Special Economic Zones (SEZs).

In this volume, authors have offered valued policy recommendations aimed at enhancing resilience and sustainability of the agriculture sector. The list of policy recommendations is not exhaustive, but they have been divided into five main sections. The first set of recommendations relates to the acceleration of agricultural productivity through innovation and training. The second and the third sets of recommendations respectively deal with the improvement of policies and institutions and the adoption of innovative financing for agriculture. The fourth set of recommendations considers the strengthening of agricultural value chains at a regional level and the last one, the development of infrastructure.

\subsection{Accelerating Agricultural Productivity Through Innovation and Training}

First of all, as demonstrated by the green revolution and the significant acceleration of agricultural productivity in Asia, ${ }^{1}$ farmers should be procured with agriculture inputs such as fertilizer, seeds, pesticides and equipment at reasonable cost. In addition to constrain productivity, the non-modernization of the sector makes it unattractive to youth. Despite the potential for "agri-preneural" activity, Africa's youth are often moving away from agriculture to get jobs in the informal service sector that provide few more opportunities for advancement (AfDB et al. 2017).

For Christelle Tchamou Meughoyi (Chap. 2), innovation in agriculture improves agricultural performances and increases the productivity of family farms. It not only provides benefits, it also brings about social change. Carren Pindiriri (Chap. 3) highlights the importance of adopting modern technology in agriculture to cope with climate change in 
sub-Saharan Africa. Drought-tolerant and water-efficient crop varieties and technologies will be fundamental requirements for developing and sustaining Africa's agriculture (Kanu et al. 2014).

Also, farmers should take advantage of recent development in Information and communication technologies (ICTs) as mobile and other information technologies help innovations in agriculture. VerdierChouchane and Karagueuzian (2016) review the successful new ICTbased services in the agriculture sector in Africa. Both at the pre-cultivation and post-harvest stages, ICTs such as mobile phone, geographical information system and remote sensing can be used for land registration, crop inventories, common information system platform, dissemination of information on market prices, traceability information, green practices and so on. By leveraging ICTs, Africa's agriculture can improve along with these new technologies and eventually reach green and inclusive growth faster than other developing regions.

For Adedoyin Mistura Rufai, Kabir Kayode Salman and Mutiat Bukola Salawu (Chap. 4), increasing productivity through better access, availability and efficient use of agricultural inputs by farmers also contributes to reducing gender productivity differentials. However, this should be complemented with a training program to build the capacity of farmers and enhance their resource use skills and production efficiency. In the same vein, Carren Pindiriri (Chap. 3) recommends the reduction of information asymmetry among farmers and increased publicity on modern technology through various media (radio, TV) to enhance sustainable development and poverty elimination. Education and formal training of smallholder farmers will increase their propensity to modernize their production systems.

Kanu et al. (2014) reaffirm that agricultural transformation in subSaharan Africa requires the strengthening of technical, financial and business management skills and capacities of the rural population. As a result of low agricultural productivity, farmers survive on subsistence income while agricultural and non-agricultural productivity gap is due to differences in skills and abilities. In essence, a movement of workers from agriculture to non-agriculture sectors does not necessarily increase productivity. Africa's low level of human capital is particularly problematic, given the pressing need to move up the value chain from the natural resource sector into a more advanced industrial sector. 


\subsection{Improving Policies and Institutions in the Agricultural Sector}

Adequate institution and support to agriculture have not been provided in sub-Saharan Africa. Generally, the lack of good governance and low public investment in agriculture have reduced incentives to private sector participation in agriculture. sub-Saharan African governments have spent on average less than $1 \%$ of national budgets on agriculture even if they pledged to spend $10 \%$ in 2003 under the terms of the New Partnership for Africa's Development (NEPAD)-CAADP (see introductory chapter). Building institutions to support the institutional development of rural Africa is of utmost importance. This section reviews more particularly the need for land reforms, gender-sensitive policies and farmers' organizations in agriculture.

Even though land reforms should be country-specific, Moyo et al. (2015) recommends that they clearly define property rights, ensure the security of land tenure and enable land to be used as collateral. For Kanu et al. (2014), the promotion of more equitable land access and rights requires both land registration and legal recognition of customary rights and administrative issues. If they cause land expropriation for smallholder farmers, pastoralists, indigenous communities and other vulnerable groups, land reforms will contribute to food insecurity and increase in poverty and inequality. For instance, land rights and administration have attracted attention in the context of biofuel production and land grabbing by large corporates. In Ghana, Lauretta S. Kemeze, Akwasi Mensah-Bonsu, Irene S. Egyir, D. P. K. Amegashie and Jean Hugues Nlom (Chap. 6) affirm that proper regulation would have avoided the massive conversion of fertile land to biofuel crops, at the expense of food crops. Jatropha cultivation (biofuel sector) could have been promoted on marginal lands so as to not compromise food security. Also, the lack of market for Jatropha seeds highlighted the need to properly regulate the sector in order to protect rural people.

Farmer support organizations are essential in acquiring, applying and continuously disseminating knowledge and skills to farmers (Kanu et al. 2014). Such organizations can help in mitigating risks and increasing 
investment. Boris Odilon Kounagbè Lokonon (Chap. 8) discusses the extent to which land tenure affects vulnerability to climate shocks, and recommends farmers' labor sharing groups and farmers' organizations. They will lessen vulnerability and raise awareness on relevant technology and good environmental management practices to increase resilience.

Besides, although women constitute most of Africa's labor force in agriculture, rules governing ownership and transfer of land rights are not favorable to women (NEPAD 2013). They face important inequalities in accessing and controlling over land, property and resources. For Kanu et al. (2014), women empowerment is needed in various forms such as policy dialogue, legal reforms, public campaigns, project development, civil society involvement and support to women groups and organizations. Land reforms should also benefit women. Adedoyin Mistura Rufai, Kabir Kayode Salman and Mutiat Bukola Salawu (Chap. 4) plead for the implementation of gender-sensitive policy. According to O. E. Ayinde, T. Abdoulaye, G. A. Olaoye and A. O. Oloyede (Chap. 5), women should be involved in the development and testing of agricultural innovation. If women farmers' preferences are incorporated in the development of agricultural technology, this will ensure food security and increased productivity.

\subsection{Innovative Financing for the Transformation of African Agriculture}

In sub-Saharan Africa, insufficient cash income and the difficult access to the financial and insurance sectors hampers farmers' ability to develop and to invest. Given the inadequate access to finance, in particular risk capital, subsistence farmers are not able to adopt new varieties and methodologies, hereby constraining agricultural productivity. For Moyo et al. (2015), Africa’s general low financial inclusion is even worse in agriculture due to the specific production cycle. ${ }^{2}$ The challenges of providing acceptable collateral for agricultural lending and adapting loan repayment 
schedules to crop cycles are huge. As a result, another means for boosting agriculture is to provide actors with the adequate financial resources.

Carren Pindiriri (Chap. 3) recommends the improvement of farmers' access to credit as it has a significant effect on farmers' decision to adopt modern technology. Financial inclusion through the establishment of rural financial institutions can significantly enhance modernization of agriculture. Regarding insurance, Francis H. Kemeze (Chap. 9) discusses the effectiveness of weather index insurance in protecting farmers against climate variability. The results are mitigated due to the specificity of the agriculture sector. Even though insurances cover basis risk, they may not cover the actual on-farm losses. Not only that they do not replace the crop loss but farmers have to buy staple food at increased price in a context of weather shocks. For this reason, the author recommends to complement weather index insurance with supplemental irrigation technology to protect farmers in case of long dry spell or severe drought.

\subsection{Strengthening Africa's Agriculture Value Chains, Trade and Competitiveness}

A major opportunity for Africa is to build regional value chains in the agro-industry as it will entail agriculture sector growth and job creation. For Kanu et al. (2014), economic potentials for small and medium enterprises are enormous throughout the agricultural value chain, given the untapped agro-industry market opportunity. Greater integration into value chains is expected to boost farmers' benefits and facilitate agribusiness. It will eventually increase trade and integration into global value chains.

Namalguebzanga C. Kafando (Chap. 10) proposes to complete agribusiness development with trade openness and regional integration policies as well as good governance to rapidly benefit from regional and global value chains. It also requires the redefinition of educational policies to efficiently use technology and the development of transport infrastructure. Infrastructure which increases agricultural productivity, reduces post-harvest loss and transportation costs, is particularly in the case of 
cross-border trade and value chain integration (Kanu et al. 2014). In the same vein, Anani N. Mensah and Abdul-Fahd Fofana (Chap. 12) plead for the improvement of international competitiveness and the support of export companies. There is a need to increase the sophistication and diversification of export products and to move away from forward integration In contrast, African countries should develop backward integration, which means that economies must import primary products from abroad to add value and produce high-tech products locally.

The creation of special economic zones and growth poles has been another means to encourage industrialization and attract foreign direct investment. Joseph Tinarwo (Chap. 10) recommends to integrate SEZ programs into national development strategies so as to ensure high-level political commitment. The author highlights the need to create joint ventures between foreign SEZ companies and local companies with the establishment of low minimum SEZ investment thresholds for local companies. Also, it is important to ensure infrastructure development within and outside the SEZ and to respond to SEZ labor requirements by aligning curricula of universities and Technical Vocational Education and Training (TVET) institutions.

\subsection{Creative Infrastructure Solutions to Boost and Transform African Agriculture}

Adequate and well-functioning infrastructure is essential for agriculture due to its positive impacts on the costs of delivering agriculture inputs and accessing market for selling outputs. However, sub-Saharan Africa's massive disadvantage in infrastructure (mainly roads, electricity and communications) has increased transaction costs and market risks, especially in small and landlocked countries. The insufficient number of roads has constituted a barrier to agricultural trade and to the adoption of productivity-enhancing inputs. For instance, Christelle Tchamou Meughoyi (Chap. 2) recommends the improvement of infrastructure to supply farmers with the fertilizers they need to adopt improved maize seeds. 
Infrastructure is also key to reduce the reliance on rain-fed agriculture and to deal with climate variability through increased irrigation. Idrissa Ouiminga (Chap. 7) highlights the positive effects of soil and water conservation techniques as an alternative to adapting to climate change. Traditional constructed structures or dug are effective to retain water and financially affordable. Zaï (seed holes dug perpendicularly to the slope and staggered), stony ropes or half-moons help farmers to combat land degradation and desertification.

\section{Notes}

1. The Green Revolution refers to the use of pesticides, the better management techniques and the introduction of improved varieties of cereals which allowed Asian countries to double the cereal production between 1970 and 1995, whereas the total land area cultivated with cereals increased by only $4 \%$. For further information on the Green Revolution, refer to Moyo et al. (2015).

2. The production cycle in agriculture consists of an initial high investment then a long period of no cash inflows during the growing season and finally, a large cash windfall after harvest, except in the case of natural or weather disaster.

\section{References}

AfDB, Organisation for Economic Co-operation and Development [OECD], \& United Nations Development Programme [UNDP]. (2017). African Economic Outlook 2017. Paris: OECD Publishing. http://www.africaneconomicoutlook.org/en/.

Kanu, B. S., Salami, A. O., \& Numasawa, K. (2014). Inclusive Growth: An Imperative for African Agriculture. Tunis: African Development Bank.

Moyo, J. M., Bah, E. M., \& Verdier-Chouchane, A. (2015). Transforming Africa’s Agriculture to Improve Competitiveness. In World Economic Forum, World Bank and AfDB, Africa Competitiveness Report 2015. Geneva: WEF. NEPAD. (2013). Agriculture and Africa - Transformation and Outlook. Johannesburg: NEPAD. 
Verdier-Chouchane, A., \& Karagueuzian, C. (2016). Moving Towards a Green Productive Agriculture in Africa: The Role of ICTs. Africa Economic Brief 7(7). Côte d'Ivoire: African Development Bank.

Open Access This chapter is licensed under the terms of the Creative Commons Attribution 4.0 International License (http://creativecommons.org/licenses/ by/4.0/), which permits use, sharing, adaptation, distribution and reproduction in any medium or format, as long as you give appropriate credit to the original author(s) and the source, provide a link to the Creative Commons license and indicate if changes were made.

The images or other third party material in this chapter are included in the chapter's Creative Commons license, unless indicated otherwise in a credit line to the material. If material is not included in the chapter's Creative Commons license and your intended use is not permitted by statutory regulation or exceeds the permitted use, you will need to obtain permission directly from the copyright holder. 